\title{
Techno-economics of carbon nanotubes produced by open air arc discharge method
}

\author{
M.S. Senthil Saravanan, S.P. Kumaresh Babu*, K. Sivaprasad, M. Jagannatham \\ Advanced Materials Processing Laboratory, Department of Metallurgical \&Materials Engineering, National institute of Technology, Tiruchirapalli, INDIA \\ *Corresponding Author: e-mail: babu@nitt.edu, Tel +91-431-2503462, Fax. +91-431-2500133
}

\begin{abstract}
This paper describes a simplified arc discharge method for synthesis of multi-walled carbon nanotubes (MWNTs). In this method, a continuous and mass production of carbon nanotubes (CNTs) can be achieved with high purity and considerable yield. There is no need for costly setup of the synthesis of MWNTs and the multistep purification, which is needed to obtain high pure MWNTs. The morphology and structure of the CNTs produced were characterized by Scanning electron microscopy (SEM), Transmission electron microscopy (TEM), X ray diffraction, Raman spectroscopy and Thermo gravimetric analysis (TGA). The cost analysis for the synthesis of MWNTs through this simplified method was done and compared with the existing commercial methods for CNT production. The production cost of the CNTs synthesized by this simplified method is $\$ 3 / \mathrm{gm}$. On comparison, it is considered to be one of the most cost effective and commercially viable production methods for MWNTs.
\end{abstract}

Keywords: Multi-walled Carbon nanotubes, X-ray diffraction, Scanning electron microscope, Transmission electron microscopy, Raman spectroscopy

\section{Introduction}

Carbon nanotubes (CNTs) have received widespread attention in the past decade owing to their unique physical, chemical, thermal and mechanical properties (Iijima, 1991). CNTs are the most promising of all nanomaterials and have been studied for their potential application in storage systems, composite materials, field emission displays, nanoscale sensors, nanoscale programmable logic circuits and other electronic applications (Popov, 2004). Since CNTs possess relatively low density (varying from 0.8 to $1.8 \mathrm{~g} / \mathrm{cc}$ for SWNTs and 1.4 to $1.8 \mathrm{~g} / \mathrm{cc}$ for MWNTs), the estimated high young's modulus and tensile strength of the nanotube reinforcements make it possible to use in composite materials for improved mechanical properties (George et al., 2005; Overney et al., 1993).

The various techniques developed to produce single and multi wall carbon nanotubes include electric arc discharge (Iijima et al., 1993; Bethune et al., 1993; Iijima et al., 1992; Ebessen et al., 1992; Journet et al., 1997), Chemical vapor deposition (Xiong et al., 2006; Vardhan et al., 2002; Liu et al., 2005; Randall et al., 2003), Laser ablation pyrolysis (Thess et al., 1996; Kroto et al., 1985; Guo et al., 1995), Plasma and laser assisted CVD (Jung et al., 2004) and mechanothermal methods (Manafi et al., 2009). In all these methods high quality nanotubes are produced with limited yield suitable for laboratory research only. The cost of production in the above methods is generally seems to be high. Apart from the major synthesis techniques, few articles from the literature discuss the production of carbon nanotubes through catalytic growth and condensation methods (Yacaman et al., 1993; Hsu et al., 1995; Cho et al., 1996). For the CNT synthesis through CVD process, the main disadvantage is the requirement of catalyst source and inert atmosphere. Although CVD method is very much familiar for the production of SWNTs which involves costly and complicated purification steps like acid functionalization when compared to the simplified method reported in this paper. Whereas in laser ablation method, the nanotubes are grown in graphite source mixed with catalyst in inert atmosphere using the laser power source. The graphite required in laser ablation process is high pure and is mostly suitable for the production of SWNTs. Even though some researchers have synthesized CNTs in simplified manner, they have used sophisticated equipment and accessories. The work reported by Yumura et al shows that MWNTs synthesized by D.C. arc discharge method and the purification was done at two different methods with varying oxidation rates (Yumura et al., 1999). Height et al synthesized single walled carbon 
nanotubes from premixed flame consists of oxy-acetylene and argon at $6.7 \mathrm{kPa}$. The metal catalyst used was $\mathrm{Fe}(\mathrm{Co})_{5}$. The characterization studies reveal the SWNTs with diameter of $1.5 \mathrm{~nm}$ (Height et al., 2004). Brichka et al produced different structure of multi walled nanotubes from low temperature synthesis of dichloromethane (Brichka et al., 2004). CNTs synthesized from thermal plasma jet were reported in Hahn et al work. In their work, Thermal plasma of Ar (99.999\%) was generated by applying a high voltage between a zirconium-containing tungsten cathode and a copper anode. The Co was used as a carbon source. The CNTs were in double and single walled structure (Hahn et al., 2004). A great challenge still exists for the synthesis of carbon nanotubes in large scale and by cost effective and straight forward process. Most of the work reported in literature using arc discharge method for CNT synthesis involves the use of controlled inert atmosphere.

This paper deals with a simplified arc discharge method for synthesis of MWNTs that eliminates nearly all of the complex and expensive machinery associated with conventional nanotubes growth techniques. A simple manual metal arc welding machine was used for this purpose and this technique proves to be a cheapest one for the production of MWNTs

\section{Experimental procedures}

Arc discharge is the best method for synthesizing both high quality multi-walled carbon nanotubes (MWNT) and single-walled carbon nanotubes (SWNT) (Sun et al., 2007). MWNTs produced by electric arc discharge method are highly crystalline and exhibit fewer defects than MWNTs produced by other methods (Grobert., 2007; Ishigami et al., 2000). For the regular Arc discharge method, it is required to have a sealed chamber, cooling circuits for electrodes and gas supplying units (Prathap et al., 2005).

A manual metal arc welding machine (ESAB SYNCHRO 300, AC/DC with current range 20-380 Amps) was used in this work. The cathode is stationary one whereas the anode is moving towards the cathode. The anode was a cylindrical graphite rod $(150 \mathrm{~mm}$ length with $10 \mathrm{~mm}$ diameter) where the cathode was a rectangular graphite plate (size: $150 \times 100 \times 10 \mathrm{~mm}^{3}$ ). The graphite electrodes used were of $98.5 \%$ purity and all of the experiments were carried out in open air atmosphere only. The arc was generated with a current of $150 \mathrm{~A}$ with $40 \mathrm{~V}$ and the arc gap between the electrodes was maintained at 1-3 mm. The current and voltage were maintained constant throughout the process. No automation of the welding set up was adopted and the arcing was made by moving the graphite rod manually towards the counter graphite plate.
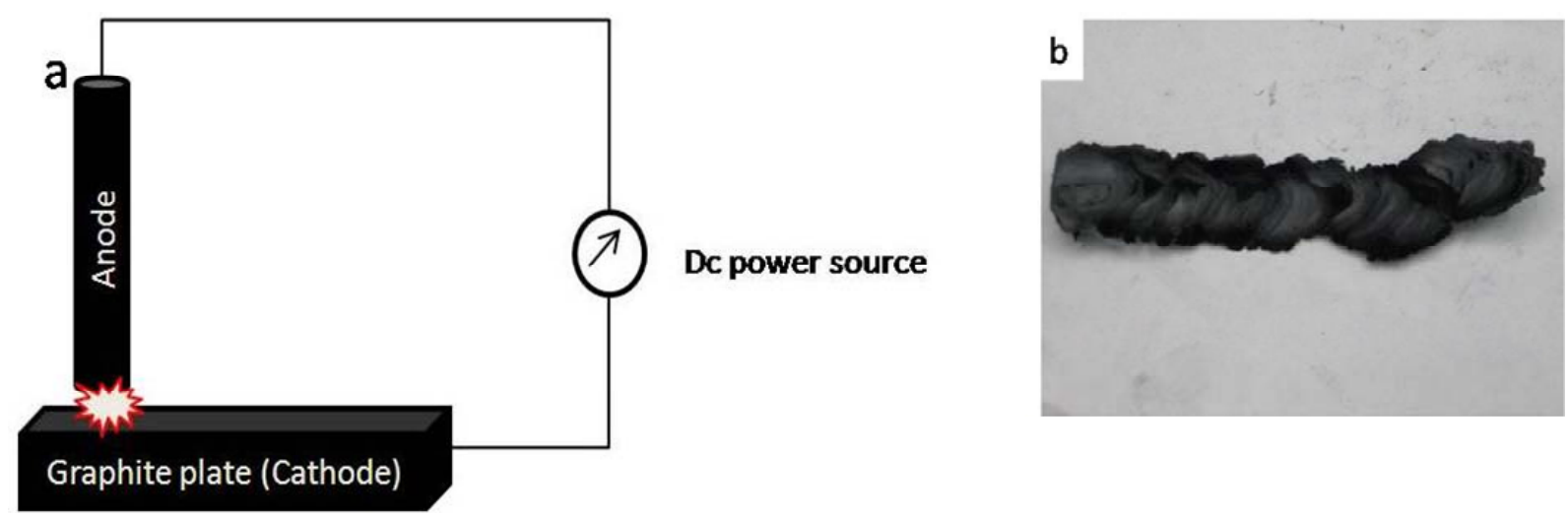

Figure1 (a) Schematic Diagram of Arc discharge set up, (b) photograph of soot produced

This carbon nanotubes synthesis process is very similar to ordinary welding process. The schematic diagram for the simplified arc discharge set up and the soot produced is shown in Fig 1.

After arcing, soot deposited on the graphite plate was scrapped and grounded into fine powder. These synthesized CNTs contain carbonaceous impurities which includes amorphous carbon, fullerenes and carbon nanoparticles.

\subsection{Purification of synthesized CNTs:}

The purification treatment consist of four steps

Step 1

The crushed powder was heated in a closed muffle furnace. All the amorphous carbon materials were burnt off by heating the soot at $650^{\circ} \mathrm{C}$ for 1 hour. 
Step 2

The heat treated CNTs were washed in distilled water and treated with toluene for 5 hours. During this step the fullerenes and the soluble impurities were removed. Then the sample was dried in air at $100^{\circ} \mathrm{C}$.

Step 3

In this step, the sample was subjected to liquid phase oxidation with $20 \%$ hydrogen peroxide for 2 hours. By this way a large amount of amorphous carbon was eliminated. Then the sample was washed with distilled water and dried in air at $100^{\circ} \mathrm{C}$. The purification in liquid phase oxidation leads to surface modification of carbon nanotubes (Li et al., 2004).

$$
\mathrm{C}+2 \mathrm{H}_{2} \mathrm{O}_{2} \longrightarrow \mathrm{CO}_{2}+2 \mathrm{H}_{2} \mathrm{O}
$$

Step 4

Then the sample was ultrasonicated in acetone for about 30 minutes so as to avoid the agglomeration of CNTs and subsequently dried in air. This causes an increase in the isolation of MWNTs. In this technique, particles are separated due to ultrasonic vibrations. Agglomerates of different nanoparticles were forced to vibrate and become more dispersed.

The purified CNTs were characterized using X- ray diffraction by RIGAKU X-ray Diffractometer with Cu K $\alpha$ radiation, SEM by FEI Quanta 200 with EDS, HRTEM by JEOL 3010 at excitation voltage of $200 \mathrm{keV}$, and Raman spectroscopy by CRM 200 with Ar ion laser $(514 \mathrm{~nm})$. To characterize the MWNTs using TEM, the samples were prepared by ultrasonicating in distilled ethyl alcohol for 5 minutes and depositing a drop of the CNTs in carbon coated TEM grid. Thermal gravimetric analysis of purified samples was carried out in Perkin Elmer STA 6000 Differential Thermal analyzer (DTA). A heating rate of $20^{\circ} \mathrm{C} / \mathrm{min}$ in argon atmosphere was maintained up to maximum temperature of $900^{\circ} \mathrm{C}$.

\section{Results and Discussion}

\subsection{XRD:}

$\mathrm{X}$ - ray diffraction is a best method for characterization of CNT structures. The XRD pattern of the purified CNTs is shown in Fig. 2.

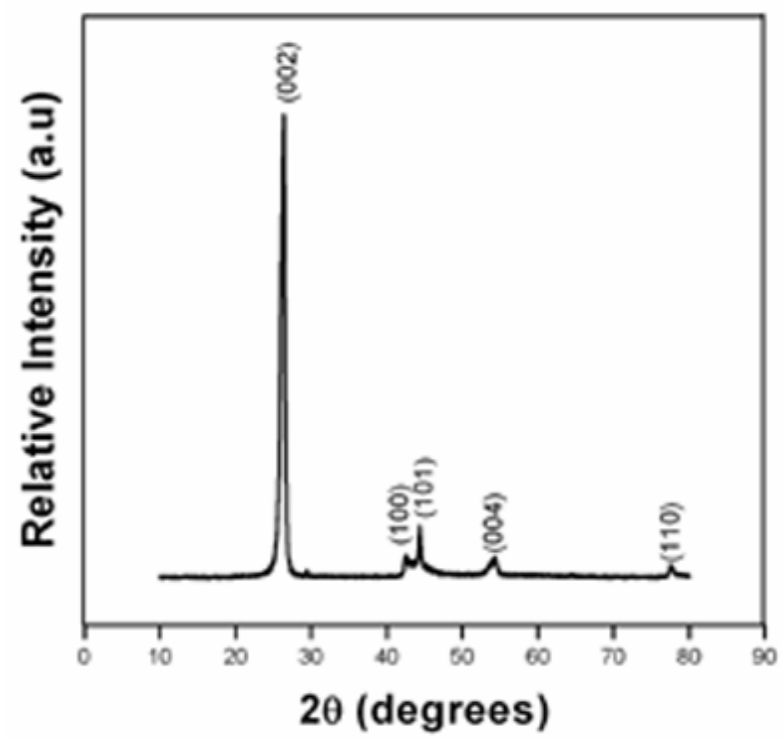

Figure 2 XRD pattern of MWNT

The peaks are indexed to the reflections of hexagonal graphite. The strong and sharp reflection peak at $26.3^{\circ}$ shows that the CNTs are crystalline in nature. The peak (002) arises due to interlayer stacking of graphene sheets (Mahanandia et al., 2008). The presence of this peak in the XRD pattern of CNTs indicates the concentric cylindrical nature of graphene sheets nested together and the nanotubes are multiwall in nature. 


\subsection{Morphology of MWNTs}

SEM micrographs of purified MWNTs are shown in Fig (3). The CNTs are seen as needle like structure in the SEM picture. The SEM picture shows densely stacked graphite layers which is formed due to the sudden quenching of plasma and high current densities used during arcing process.

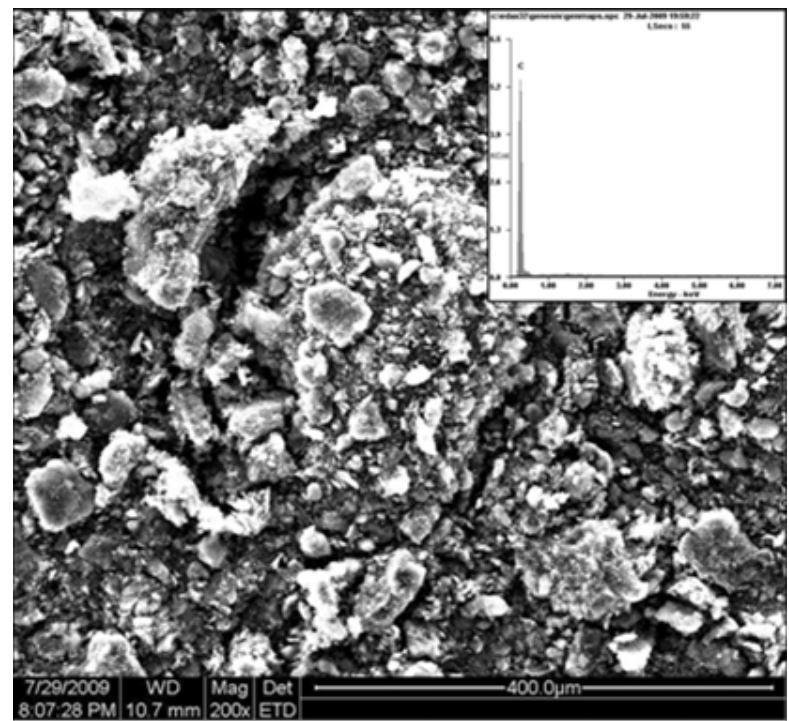

Figure 3 SEM micrograph of MWNTs; EDS analysis shows the high pure Carbon

The inset shows the EDS analysis which reveal that the MWNTs synthesized were in high pure and good crystallinity since no other elements found in the analysis. TEM investigations are carried out at an excitation voltage of $200 \mathrm{KeV}$ and the images of the purified CNTs are shown in Fig. 4.

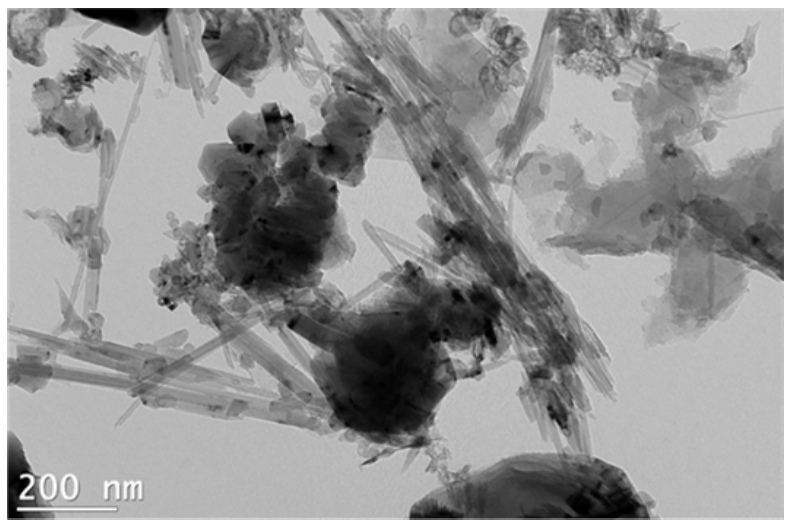

Figure 4 TEM images shows the presence of CNTs with polyhedral nanoparticles

The net yield of CNTs produced by this method can be calculated from the low magnification TEM image. It is found that more than $75 \%$ of MWNTs are present in deposit and the remaining are polyhedral nano particles and other graphitic nano particles with few double walled carbon nanotubes. The polyhedral particles were generated by the insufficient ion supply during arcing process which plays a key role in the formation of nanotubes (Joshi et al., 2008). From the TEM studies, it is seen that the carbon nanotubes were multiwall in nature with an outer diameter of $16 \mathrm{~nm}$ and inner diameter of $3.5 \mathrm{~nm}$. Fig. 5 inset image shows the characteristic $0.34 \mathrm{~nm}$ inner layer spacing which provides evidence that highly ordered pyrolytic graphite matches with graphite layer spacing. 


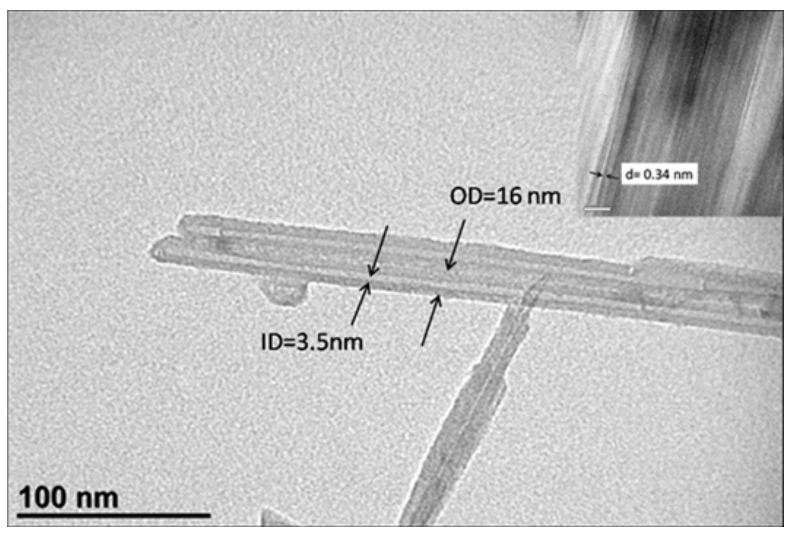

Figure 5 TEM images of CNTs with OD and ID, inset shows the interplanar spacing

Further investigation on the TEM pictures in Fig. 6 show that some of CNTs are in conical shaped. This is due to the reason that the apexes of the cone moved out of high temperature zone, the reactivity of the tubes were lost and the bottom part exposed to the plasma region and the sudden quenching leads to growth into conical shaped CNTs

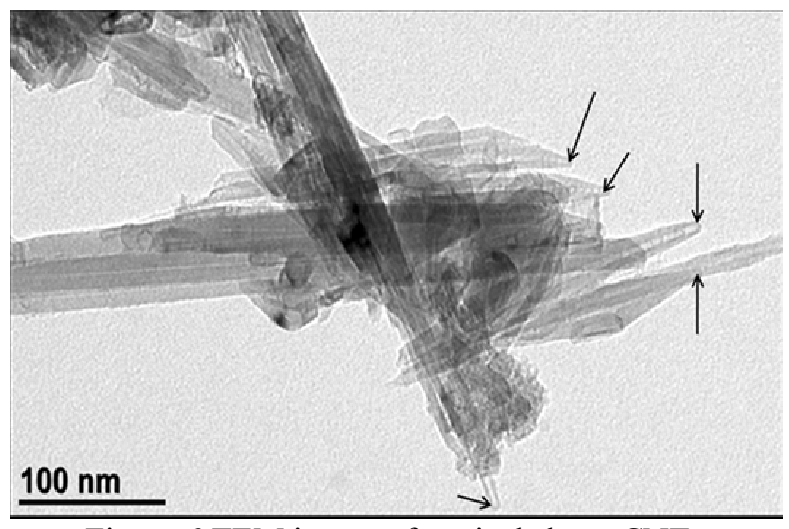

Figure 6 TEM image of conical shape CNTs

Carbon nanotubes synthesized in open air atmosphere having such morphologies was reported in Joshi et al (2008). The length of the CNTs varies from 0.5 to $1 \mu \mathrm{m}$ shown in fig (7) with selected area electron diffraction (SAED) pattern of MWNTs.

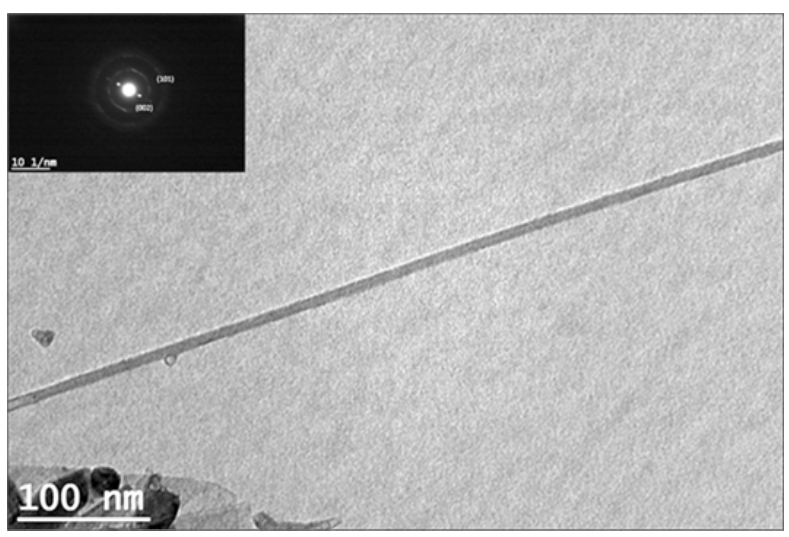

Figure7 TEM image of single MWNT; inset shows the SAED pattern of MWNTs

The diffractive rings show that MWNTs possess a low degree of graphite and it is confirmed through x-ray diffraction pattern also. TEM observation confirms that the CNTs were hollow centered with outer diameter $16 \mathrm{~nm}$ with wall thickness of $7 \mathrm{~nm}$. The CNTs are made of parallel graphene planes oriented along the tube axis with amorphous carbon structure attaching onto their outer surfaces.

\subsection{Raman Studies}

Raman Spectra shown in Fig (8) provides information about the presence of disorder in CNT samples. 


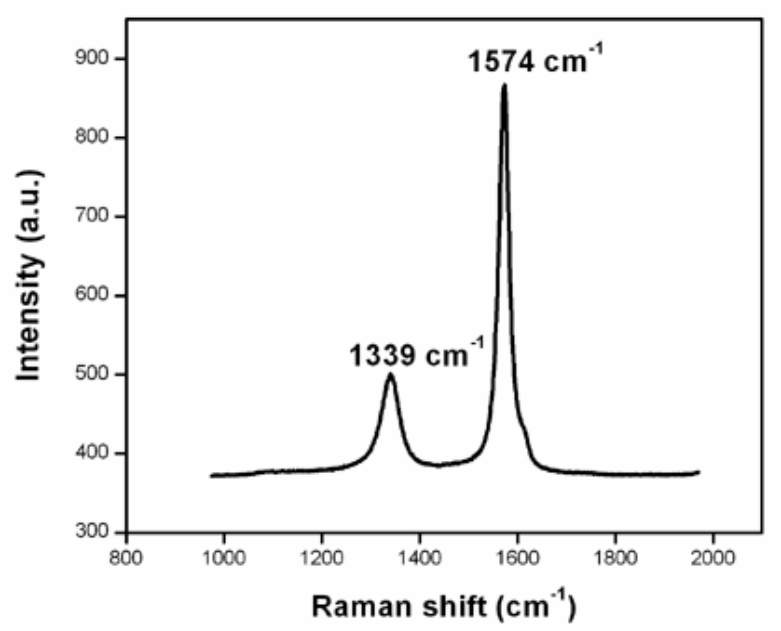

Figure 8 Raman spectra of CNTs

Two strong peaks at $1338 \mathrm{~cm}-1$ and $1571 \mathrm{~cm}-1$ were shown in the spectrum. The peak at $1571 \mathrm{~cm}-1$ is due to the vibration of carbon atoms of the graphite called first order G-band. The next peak at $1338 \mathrm{~cm}-1$ called the D-band is due to the vibrations of carbon atoms with dangling bonds in the disordered plane structure (Yuan et al., 2008). The intensity ratio of D- band to G- band (ID/IG) is 0.57 , which shows that CNTs exhibit a low degree of order for graphitic particles

The result from Raman spectra shows that CNTs exhibit good crystallinity with some defects or carbonaceous particles which confirms the HRTEM and XRD results.

\subsection{TGA studies:}

Thermo gravimetric analysis of purified MWNTs was carried out in argon atmosphere which is shown in Fig. 9.

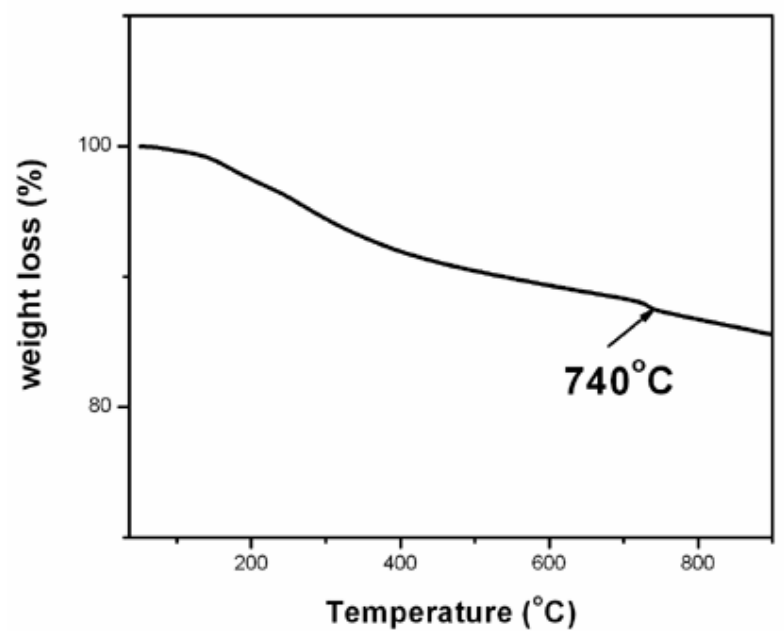

Figure 9 Thermo gravimetric analyses of MWNTs

The different forms of carbon show different oxidation behaviors. From TGA curve, less ordered amorphous carbon were burnt around $350^{\circ} \mathrm{C}$ due to the low activation energy. The well graphitic particles start to oxidize at high temperature around $600^{\circ} \mathrm{C}$. Ajayan et al reported that the true oxidation initiation temperature of MWNTs is $700^{\circ} \mathrm{C}$ (Ajayan et al., 1993). The TGA curve consist of broad peak at $740^{\circ} \mathrm{C}$ which may be attributed to the oxidation of graphitic impurities which are more stable to thermal oxidation and burned at higher temperature. In this work, the air oxidation treatment was done up to $600^{\circ} \mathrm{C}$.

\section{Techno-economics of producing CNTs by this method}

Table 1 explains various purification stages and the mass variations during each purification stages in the present work. Based on this, each step in purification table is having a definite purpose of removing some impurities to obtain pure CNTs. The term yield is relatively varying from author to author as some reports that yield is based on removing only metallic particles and others reports that it is removing all unnecessary things other than CNTs. In the present investigation it is believed that yield is based on second argument. Hence, even though it appears to be lower yields, the cost-effective yield is more in the present route of 
synthesis due to cheap route of synthesis. The major differences in cost of synthesizing CNTs by various routes are projected in Table 2. Even though CVD process is the widely used route of synthesizing CNTs, the cost associated with that is very high. Unless a particular functional property demands a very high purity of CNTs, it is not economical to adopt this route of synthesis. Among other processes, laser ablation is considered to be very costly effort and hence it is not commercially viable and nowhere is it in practice. Although the conventional arc discharge method and present arc discharge method appears to be more common, the major difference is the vacuum and associate cost of conventional arc discharge method. The yield appears to be slightly better in the conventional arc discharge method, may be due to less tendency of oxidation of the carbonaceous matter in graphite. However, the cost effective yield associated with simplified arc discharge method is more promising and economically viable.

Table: 1 Stages of purification and effective mass variation during each step

\begin{tabular}{|r|l|l|l|l|}
\hline SI No & Purification Step & Initial Mass & Purpose & Final Mass \\
\hline 1. & Air oxidation & $1.920 \mathrm{~g}$ & Removal of carbonaceous particle & $1.367 \mathrm{~g}$ \\
\hline 2. & Solvent Treatment & $1.367 \mathrm{~g}$ & Removal of fullerences and the soluble impurities & $1.239 \mathrm{~g}$ \\
\hline 3. & Liquid oxidation & $1.239 \mathrm{~g}$ & Removal of amorphous carbon & $1.190 \mathrm{~g}$ \\
\hline 4. & Ultrasonication & $1.190 \mathrm{~g}$ & De agglomeration of CNTs & $1.190 \mathrm{~g}$ \\
\hline \multicolumn{2}{|l}{ Total yield = Final mass/Initial mass $=61.79 \%$} & \\
\hline
\end{tabular}

Table: 2 Effective costs involved in producing CNTs by various methods

\begin{tabular}{|c|c|c|c|}
\hline Method & Set up & Purity & Approx. Cost in USD \\
\hline $\begin{array}{l}\text { Conventional arc } \\
\text { discharge in vacuum }\end{array}$ & $\begin{array}{l}\text { TIG power source, Inert } \\
\text { atmosphere, metal cabinet } \\
\text { with water cooling system, } \\
\text { automated process and } \\
\text { Chemical purification }\end{array}$ & $80-95$ wt $\%$ & $\begin{array}{l}\text { 15\$/gm } \\
\text { (www.cheaptubes.com) }\end{array}$ \\
\hline CVD & $\begin{array}{l}\text { Furnace, inert atmosphere, } \\
\text { metal catalyst, }\end{array}$ & $95 \%$ & $\begin{array}{l}\text { 40\$/gm } \\
\text { (www.helixmaterial.com) }\end{array}$ \\
\hline Laser ablation & $\begin{array}{l}\text { Laser source, Furnace, } \\
\text { inert atmosphere, Metal } \\
\text { catalyst-graphite } \\
\text { composite }\end{array}$ & $20-80 \mathrm{wt} \%$ & $\begin{array}{l}\text { Due to the high capital cost of the laser and the } \\
\text { fewer quantity of CNT after final purification, } \\
\text { this method is not commercially viable. } \\
\text { (Karthikeyan et al., 2009) }\end{array}$ \\
\hline Floating Catalyst method & $\begin{array}{l}\text { Tubular reactor, quartz } \\
\text { tube, thermocouples, inert } \\
\text { gas }\end{array}$ & $70-90 \mathrm{wt} \%$ & $\begin{array}{l}\text { It needs a complicated set up. The cost of } \\
\text { aromatic hydro carbons is very high (Benzene: } \\
44 \$ / 10 \mathrm{~g}) \text { (Fan et al., 2006) }\end{array}$ \\
\hline Cyclic oxidation & $\begin{array}{l}\text { Plant materials, ceramic } \\
\text { reactor }\end{array}$ & $\begin{array}{l}\text { No reports on } \\
\text { purity }\end{array}$ & $\begin{array}{l}\text { Even though the source materials are cheap, pre } \\
\text { treatment and heating takes longer duration in a } \\
\text { high pressure vacuum chamber. Yield details } \\
\text { are not available } \\
\text { (Xie et al., 2009) }\end{array}$ \\
\hline EDM process & $\begin{array}{l}\text { Plasma sputtering unit, } \\
\text { Microelectric discharge } \\
\text { apparatus, metal catalyst }\end{array}$ & $\begin{array}{l}\text { No reports on } \\
\text { purity }\end{array}$ & $\begin{array}{l}\text { It requires costly equipments such as plasma } \\
\text { sputtering unit and micro electric discharge } \\
\text { unit. Yield details are not mentioned. } \\
\text { (Tsai et al., 2008) }\end{array}$ \\
\hline Combustion process & $\begin{array}{l}\text { Bunsen burner, liquefied } \\
\text { butane, metal catalyst }\end{array}$ & $\begin{array}{l}\text { No reports on } \\
\text { purity }\end{array}$ & $\begin{array}{l}\text { This method is simple but the yield seems to be } \\
\text { very less compared to other methods (in mg). } \\
\text { (Hsieh et al., 2008) }\end{array}$ \\
\hline $\begin{array}{l}\text { Simplified arc discharge } \\
\text { in air }\end{array}$ & $\begin{array}{l}\text { Manual Metal arc welding } \\
\text { machine and Chemical } \\
\text { purification }\end{array}$ & $75-80 \mathrm{wt} \%$ & $3 \$ / \mathrm{gm}^{*}$ \\
\hline
\end{tabular}

*COST ANALYSIS:

Conventional Arc discharge method (Approximate break up cost analysis):

TIG power source: 300 INR, Chemicals: 100 INR; Vacuum and Furnace power: 150 INR; Inert gas: 200 INR;

Total: 750 INR (15 USD) 


\section{CVD (Approximate break up cost analysis):}

Furnace power: 150 INR, Inert Gas: 200 INR; Metal Catalyst: 200 INR; Hydrocarbons: 1200 INR; Chemicals: 250 INR; Total: 2000 INR (40 USD).

\section{Simplified Arc discharge Method}

Metal arc power source: 40 INR; Furnace power source: 10 INR; Chemicals: 100 INR; Total: 150 INR (3 USD)

The methods apart from arc discharge, CVD and laser ablation are not in commercial and large scale synthesis of CNTs and they are still in laboratory research level only.

\section{Conclusions}

Multiwall CNTs with a small amount of polyhedral particles were synthesized successfully in open air with a considerable yield through a simple and cost effective arc discharge method. The multiwall structure has been analyzed by Scanning electron microscopy (SEM), Transmission electron microscopy (TEM), X ray diffraction and Raman spectroscopy. The oxidation behavior has been studied using thermo gravimetric analysis. This method can be proposed for commercial production of multi wall CNTs with no complicated control of parameters. This method is quantitatively proved as cheapest one. The cost-effective yield of multiwall carbon nanotubes produced by this process was high compared to conventional arc discharge method and other methods also. As a part of future study, a detailed break up cost analysis should be carried out for other methods such as Floating Catalyst method, Combustion process, EDM process and cyclic oxidation. This study highlights an overall Techno-economics of CNT production and will pave a way for exploring the use of CNTs in various applications effectively.

\section{References}

Ajayan, P.M, Ebbesen, T.W, Ichihasi, T., Iijima, S., Tanigaki ,K., Hura, H. 1993. Opening carbon nanotubes with oxygen and implications for filling, Nature, Vol. 362, pp 522-525.

Bethune, D.S., Kiang, C.H., De Vries, M.S., Gorman,G., Savoy,R., Vasques,J and Beyers, R. 1993. Cobalt-catalysed growth of carbon nanotubes with single-atomic-layer walls, Nature, Vol. 363, pp 605-607.

Brichka, S.Ya., Prikhod'ko, G.P., Sementsov, Yu.I., Brichka, A.V., Dovbeshko, G.I., Paschuk, O.P. 2004. Synthesis of carbon nanotubes from a chlorine-containing precursor and their properties, Carbon, Vol.42, pp 2581-2587.

Cho,W.S., Hamada, E., Kondo,Y., Takayanagi, K. 1996. Synthesis of carbon nanotubes from bulk polymer, Applied Physics Letters, Vol. 69, pp 278-279

Ebessen, T.W and Ajayan, P. 1992. Large scale synthesis of carbon nanotubes, Nature, Vol.358, pp 220-222.

Fan, Y.Y., Kaufmann, A., Mukasyan, A., Varma A. 2006. Single- and multi-walled carbon nanotubes produced using floating catalyst method: synthesis, purification and hydrogen up-take, Carbon, Vol. 44, pp. 2160-2170.

George R, Kashyap K.T., Rahul R, Yamdagni S., 2005. Strengthening in Aluminium/CNT Composites, Scripta Materialia, 53, pp. 1159-1163.

Grobert, N. 2007. Carbon nanotubes - Becoming clean, Materials Today, Vol. 10, pp 28-35.

Guo,T., Nikolaev,P., Colbert, D.T., Smalley, R.E. 1995. Catalytic growth of single-walled nanotubes by laser vaporization, Chemical Physics Letters, Vol.243, pp 49-54.

Hahn J., Han J.H., Yoo J.-E., Jung H.Y., Suh J.S. 2004. New continuous gas-phase synthesis of high purity carbon nanotubes by a thermal plasma jet, Carbon, Vol.42, pp 877-883.

Height M.J., Howard J.B., Tester J.W., Vander Sande J.B. 2004. Flame synthesis of single-walled carbon nanotubes, Carbon, Vol.42, pp 2295-2307.

Hsu, W.K., Hare, J.P., Terrones,M., Kroto, H.W., Walton,D.R.M., Harris,P.J.F. 1995. Condensed phase nanotubes, Nature, Vol. 377, pp 687.

Hsieh, C.C., Youh, M.J., Wu, H.C., Hsu, L.C., Guo, J.C., Li, Y.Y. 2008. Synthesis of carbon nanotubes using a butane- air bunsen burner and the resulting field emission characteristics', J.Phys.Chem.C, Vol. 112, pp. 19224-19230.

Iijima,S., Ajayan,P., Ichihasi,T., 1992. Growth model for carbon nanotubes, Physical Review Letters, Vol. 69, pp 3100-3103.

Iijima, S. 1991. Helical Microtubules of graphitic carbon, Nature, Vol. 354, pp. 56-58.

Iijima. S and Ichihasi.T, 1993. Single-shell carbon nanotubes of 1-nm diameter, Nature, Vol. 363, pp 603-605.

Ishigami,M., John Cumings, Zettal,A., Chen, S. 2000. A simple method for the continuous production of carbon nanotubes', Chemical Physics Letters, Vol. 319, pp 457-459.

Journet, C., Maser, W. K., Bernier, P., Loiseau, A., Lamy de la Chappelle, M., Lefrant, S., Deniard, P., Lee, R. Fischer, J. E., 1997. Large-scale production of single-walled carbon nanotubes by the electric-arc technique', Nature, Vol. 388, pp 756-758.

Joshi, R., Engstler, J., Nair,P.K., Haridoss,P., Schneider J.J. 2008. High yield formation of carbon nanotubes using a rotating cathode in open air, Diamond and Related Materials, Vol.17, pp 913-919.

Jung,K.H., Boo,J.H., Hong, B. 2004. Synthesis of carbon nanotubes grown by hot filament plasma-enhanced chemical vapor deposition method. Diamond and Related Materials, Vol. 13, pp 299-304. 
Karthikeyan, S, Mahalingam, P., Karthik, M. 2009. Large scale synthesis of carbon nanotubes, E-journal of Chemistry, Vol. 6, pp. $1-12$.

Kroto, H.W., Heath, J.R., O’Brien, S.C., Curl, R.F. 1985. C-60: Buckminster fullerene, Nature, Vol. 318, pp 162-163

Liu, B.C., Yu, B., Zhang, M.X. 2005. Catalytic CVD synthesis of double-walled carbon nanotubes with a narrow distribution of diameters over $\mathrm{Fe}-\mathrm{Co} / \mathrm{MgO}$ catalyst', Chemical Physics Letters, Vol. 407, pp 232-235

Li,C., Wang, D., Liang, T., Wang, X., Wu, J., Hu, X., and Liang, J. 2004. Oxidation of multiwalled carbon nanotubes by air: Benefits for electric double layer capacitors', Powder Technology, Vol. 142, pp 175-179.

Mahanandia, P., Vishwakarma, P.N., Nanda, K.K., Prasad, V., Barai, K., Mondal, A.K., Sarangi, S., Dey G.K., Subramanyam, S.V. 2008. Synthesis of MWNTs by simple pyrolysis, Solid State Communications; Vol. 145, pp 143-148.

Manafi, S.A., Amin, M.H., Rahimipour, M.R., Salahi, E., Kazemzadeh, A. 2009. Carbon nanotubes synthesized by Mechanothermal method, New Carbon Materials, Vol. 24, pp 39-44.

Overney,G., Zhong, W. and Tománek, D. 1993. Structural rigidity and low frequency vibrational modes of long carbon tubules', Zeitschrift für Physik D, Vol 27, pp 93-96.

Prathap Haridoss, Nair,P.K., Maneesh, K. Palagudu, M.C. 2005. Synthesis of carbon nanotubes by arc discharge in open air, Journal of Nanoscience and Nanotechnology, Vol. 5, pp 747-752.

Popov V.N., 2004. Carbon nanotubes: properties and applications, Material Science and Engineering R, Vol. 43, pp. 61-102.

Sun X., Bao W., Lv Y., Deng J. and Wang X.. 2007. Synthesis of high quality single-walled carbon nanotubes by arc discharge method in large scale, Materials Letters, Vol.61, pp 3956-3958.

Tsai, Y.Y., Su.J.S., Su, C.Y. 2008. A novel method to produce carbon nanotubes using EDM process, Int,J, Machine Tools \& Manufacture, Vol. 48, pp. 1653-1657.

Thess, A., Lee, R., Nikolaev, P., Dai,H., Petit, P., Robert, J., Xu, C., Lee, Y.H., Kim, S.G., Rinzler, A.G., Colbert, D.T.,Scuseria, G.E., Tománek, D., Fischer, J.E., Smalley, R.E., 1996. Crystalline ropes of metallic carbon nanotubes, Science, Vol. 273, pp 483-487.

Vardhan, V.K and Xie, J. 2002. Large-scale synthesis of multi-walled carbon nanotubes by microwave CVD, Smart Materials and Structures, Vol. 11, pp 610-616

Vander Wal. R.L., Hall L.J. 2003. Carbon nanotube synthesis upon stainless steel meshes, Carbon, Vol. 41, pp 659-672.

www.cheaptubes.com, downloaded 18/06/2010

www.helixmaterial.com, downloaded 18/06/2010

Xie, X., Goodell, B., Qian, Y., Danial, G., Zhang, D., Nagle, D.C., Peterson M.L., Jellison, J. 2009. A method for producing carbon nanotubes directly from plant materials, Forest Products Journal, Vol. 59, No. 1-2, pp. 26-28.

Xiong, G.Y., Wang,D.Z, Ren,Z.F. 2006. Aligned millimeter-long carbon nanotube arrays grown on single crystal magnesia, Carbon, Vol.44, pp 969-973

Yacaman, M.J., Yoshida, M.M., Rendon, L., Santiesteban, J.G. 1993. Catalytic growth of carbon microtubules with fullerene structure, Applied Physics Letters, Vol. 62, pp 202-204.

Yumura, M., Ohshima, S., Uchida, K., Tasaka, Y., Kuriki, Y., Ikazaki, F., Saito, Y., Uemura, S. 1999. Synthesis and purification of multi-walled carbon nanotubes for field emitter applications, Diamond and Related Materials Vol. 8, pp 785-791.

Yuan, D., Liu, Y., Xia, Y., Chen, L. 2008. Preparation and characterization of Z-shaped carbon nanotubes via decomposing magnesium acetate, Material Chemistry and Physics, Vol. 112, pp. 27-30.

\section{Biographical notes}

M.S.Senthil Saravanan is a doctoral student in the Department of Metallurgical and Materials Engineering, NIT, Trichy. His research area is synthesis of carbon nanotubes and Al-CNT nanocomposites.

Dr. S.P. Kumaresh Babu received his Ph.D from National Institute of Technology, Trichy, India in 2006. In 2007, he is working as Associate Professor in the Department of Metallurgical and Materials Engineering, NIT, Trichy. His research interests are in the area of Nanocomposites, Powder Metallurgy, Casting, Surface Engineering, hard facing and corrosion.

Dr. K. Sivaprasad is currently working as Assistant Professor in the Department of Metallurgical and Materials Engineering, NIT, Trichy, India. He was awarded $\mathrm{Ph} . \mathrm{D}$ from Indian Institute of Technology Madras, Chennai in 2007. His research areas are Cryorolling, Nanocomposites, Mechanical Behavior, welding and Powder Metallurgy

M. Jagannatham is currently an M.Tech student in the Department of Metallurgical and Materials Engineering, NIT, Trichy. His research areas are synthesis of carbon nanotubes and CNT-metal matrix composites

Received April 2010

Accepted May 2010

Final acceptance in revised form June 2010 